\title{
Horizontal Long Axis of Heart
}

National Cancer Institute

\section{Source}

National Cancer Institute. Horizontal Long Axis of Heart. NCI Thesaurus. Code C94907.

An oblique plane through the heart containing its long axis and showing all 4 chambers.

This and any plane parallel to it can be called a horizontal long axis view. These slices are perpendicular to vertical long axis views as well as short axis views. 